\title{
Capsule Commentary on Young et al., Internal Medicine Residents' Perceived Responsibility for Patients at Hospital Discharge: A National Survey
}

\author{
Shobha W. Stack, MD, PhD \\ Division of General Internal Medicine, University of Washington Medical Center, Seattle, WA, USA.
}

$\mathrm{J}$ Gen Intern Med 31(12): 1508

DOI: $10.1007 / \mathrm{s} 11606-016-3859-\mathrm{z}$

(c) Society of General Internal Medicine 2016

$\mathrm{W}$ hen do you cut the cord? Young et al. ${ }^{1}$ reignite the debate regarding when a hospitalist's responsibility for the patient should end. ${ }^{2}$ In this multi-center study, residents were surveyed on their perceived duration of post-discharge responsibility. With results strikingly similar to those of a prior study in which $28.5 \%$ of career hospitalists believed that their responsibility ended at discharge, ${ }^{3}$ the authors found that $26 \%$ of residents believed that their responsibility ended at discharge, with $43.3 \%$ at $\leq 7$ days and $19.3 \%$ at $15-30$ days after discharge.

Given the enthusiasm with which the study and standardization of discharge practices has been undertaken in the field of hospital medicine, ${ }^{4}$ the variation in perceived responsibility at first seems incongruent. One of the core principles of the transitions of care consensus policy statement ${ }^{5}$ is that "at every point of transitions the patient and/or their family/caregivers need to know who is responsible for their care at that point." Yet the statement is appropriately vague regarding timing, noting that the transfer of responsibility must occur "within a reasonable time frame" that allows for dissemination and clarification of relevant patient information. Perhaps this is accomplished on the day of discharge with a phone call, or perhaps it is completed 7 days later when pending lab results are received. The variation in resident responses could actually be a reflection of these scenarios with the underlying principle in mind. On the other hand, this heterogeneity could also reflect a lack of understanding of the shared responsibility between inpatient and outpatient providers that is needed during transitions of care.
In the end, the residents were not necessarily wrong in perceiving that their responsibility ended at discharge, 7 days, or 30 days, because the question asked of them belies one that is more complex. In the period between hospital and clinic, whom should the patient call if they have questions about their discharge medications? Whom should they call if a new issue arises? The answer lies less in a number and more in cultivating a teachable attitude of collaboration between hospitalists and primary care providers throughout this vulnerable time.

Corresponding Author: Shobha W. Stack, MD, PhD; Division of General Internal MedicineUniversity of Washington Medical Center, Seattle, WA, USA (e-mail: shobhaws@uw.edu).

\section{Compliance with Ethical Standards:}

Conflict of Interest: The author has no conflicts with this article.

\section{REFERENCES}

1. Young E, Stickrath C, McNulty M, Calderon AJ, Chapman E, Gonzalo JD, Kuperman E, Lopez M, Smith CJ, Seigart JR, Theobald CN, Burke RE. Internal medicine residents' perceived responsibility for patients at hospital discharge: a national survey. J Gen Intern Med; doi: 10.1007/ s11606-016-3855-3

2. Beresford L. Hospitalists' responsibility, role in readmission prevention. The Hospitalist. 2015;19(4): 1 .

3. Burke RE, Ryan PR. Postdischarge clinics: hospitalist attitudes and experiences. J Hosp Med. 2013;8(10):578-81.

4. Jack BW, Paasche-Orlow MK, Mitchell SM, et al. An overview of the ReEngineered Discharge (RED) toolkit. (Prepared by Boston University under Contract No. HHSA290200600012i.) Rockville, MD: Agency for Healthcare Research and Quality; March 2013. AHRQ Publication No. 12(13)-0084.

5. Snow V, Beck D, Budnitz T, et al. Transitions of care consensus policy statement: American College of Physicians, Society of General Internal Medicine, Society of Hospital Medicine, American Geriatrics Society, American College of Emergency Physicians, and Society for Academic Emergency Medicine. J Hosp Med. 2009;4(6):364-70. 